\title{
OPTIMASI CELAH PITA OPTIK OPAL DAN CORE-SHELL OPAL
}

\author{
Muldarisnur \\ Jurusan Fisika, FMIPA - Universitas Andalas \\ Kampus Limau Manis, Pauh, Padang 25163 \\ e-mail : mulda.muldarisnur@gmail.com
}

\begin{abstract}
ABSTRAK
Kristal fotonik merupakan platform ideal untuk pengembangan devais optik terintegrasi. Interaksi antara foton dengan modulasi periodik pada indeks bias mengakibatkan terbentuknya celah pita optik yang memberi peluang untuk mengontrol perambatan dan emisi cahaya serta interaksinya dengan bahan. Kristal fotonik tiga dimensi biasanya difabrikasi menggunakan teknik self-assembly karena selain murah dan mudah dilakukan, teknik ini dapat digunakan untuk membuat kristal dengan berbagai periodisitas. Opal hanya memiliki celah pita optik pada arah tertentu saja (stop band) tapi dapat dimodifikasi atau digunakan sebagai template untuk inverse opal yang memiliki celah pita optik dalam segala arah (omnidirectional). Lebar stop band dari opal dan core-shell opal akan dioptimasi dengan memvariasikan indeks bias medium dan struktur kristal. Hasil simulasi menunjukkan bahwa opal dengan partikel tidak saling bersentuhan memiliki stop band terlebar dan memiliki potensi untuk digunakan sebagai devais optik.
\end{abstract}

Kata Kunci : Kristal fotonik, opal, core-shell opal, celah pita optik, plane-wave expansion method.

\begin{abstract}
Photonic crystals, periodically arranged materials, have been intensively investigated currently due to their interesting optical properties that allow for fabrication of highly-integrated and highperformance optical devices. Bragg diffraction at the periodic interfaces of two different materials results in the formation of optical band gap. Despite having higher accuracy and better control in the fabrication processes, lithographic techniques are slow and expensive. Therefore, selfassembly of colloidal particles to form the so-called artificial opals becomes the most widely adapted approach for fabrication of three-dimensional photonic crystals. Opals possess a partial or stop band only, but they can be modified or used to form inverse opals with a complete band gap. In this work, the size of the stop band of opals and core-shell opals will be numerically optimized by using plane wave expansion method. We found that non close-packed opals have a large stop band that is suitable for application in optical devices.
\end{abstract}

Keywords : photonic crystals, opals, core-shell opal, optical band gap, plane wave expansion method.

\section{PENDAHULUAN}

Sistem komunikasi optik sekarang ini masih bergantung pada piranti elektronik untuk melakukan fungsi seperti penguatan dan routing sinyal. Komponen elektronik sayangnya bersifat disipatif dan tidak mampu mengimbangi kecepatan transmisi sinyal pada serat optik (Bagad, 2008). Hal ini mendorong pengembangan sistem komunikasi yang sepenuhnya menggunakan piranti optik. Integrasi berbagai piranti optik yang berfungsi sebagai sumber cahaya, pemandu gelombang, routing, dan penguatan sinyal sayangnya tidak dapat dilakukan menggunakan sistem optik konvensional berdasarkan prinsip pemantulan dan pembiasan. 
Pelemahan sinyal dan difraksi pada sistem optik konvensional dapat diatasi dengan menggunakan struktur periodik yang dikenal sebagai kristal fotonik (Yablonovitch, 1987) dan (John, 1987). Kristal fotonik adalah struktur yang memiliki modulasi indeks bias secara periodik pada skala panjang gelombang cahaya. Kristal fotonik memiliki celah pita optik yang memungkinkan manipulasi perambatan cahaya dan kontrol atas interaksi cahaya dengan bahan. Di dalam kristal fotonik, cahaya dapat dipandu tanpa pelemahan intensitas dan emisi spontan dapat dihilangkan. Kristal fotonik dipercaya merupakan platform ideal untuk merealisasikan all-optical chips (Joannopoulous dkk., 2008).

Sementara piranti optik dari kristal fotonik satu dan dua dimensi sudah mendekati tahap komersialisasi, struktur periodik tiga dimensi berkualitas tinggi masih sulit difabrikasi. Meskipun sangat akurat, teknik litografi sangat mahal, lambat dan tidak akurat ketika jumlah lapisan bertambah. Oleh karena itu, self-assembly partikel koloid membentuk kristal yang dikenal dengan opal menjadi pendekatan utama untuk fabrikasi struktur periodik tiga dimensi karena mudah dilakukan, cepat, dan murah.

Dalam makalah ini, lebar celah pita optik opal dan core-shell opal akan dioptimasi secara numerik dengan memvariasikan ukuran partikel koloid dan indeks bias medium.

\section{TINJAUAN PUSTAKA}

Sifat optik kristal fotonik dapat dijelaskan dengan menggunakan konsep fisika zat padat. Perambatan foton di dalam medium dengan modulasi indeks bias periodik mirip dengan gerakan elektron di bawah pengaruh distribusi potensial atom. Cahaya polikromatik merambat tanpa gangguan di dalam kristal fotonik karena efek hamburan saling menghilangkan kecuali untuk cahaya yang memenuhi kondisi Bragg (Johnson dan Joannopoulous, 2002). Interaksi kuat antar cahaya dan struktur periodik mengakibatkan terjadinya interferensi destruktif cahaya yang dipantulkan pada bidang batas antara dua medium yang berbeda. Interferensi destruktif menyebabkan terbentuknya celah pita optik dimana cahaya dengan rentang frekuensi tertentu tidak dapat merambat atau dihasilkan dalam kristal fotonik. Posisi celah pita kristal fotonik tergantung pada struktur kristal, periodisitas, dan kontras indeks bias antara material penyusunnya.

Perambatan cahaya dalam kristal fotonik dapat dijelaskan menggunakan persamaan Maxwell. Persamaan gelombang yang merambat diturunkan dari persamaan Maxwell dengan melakukan prosedur dekopling medan listrik dan medan magnet, sehingga dihasilkan persamaan:

$$
\begin{aligned}
& \frac{1}{\varepsilon(\mathbf{r})} \nabla \times(\nabla \times \mathbf{E}(\mathbf{r}, t))=-\frac{1}{c^{2}} \frac{\partial^{2} \mathbf{E}(\mathbf{r}, t)}{\partial t^{2}} \\
& \nabla \times\left(\frac{1}{\varepsilon(\mathbf{r})} \nabla \times \mathbf{H}(\mathbf{r}, t)\right)=\frac{1}{c^{2}} \frac{\partial^{2} \mathbf{H}(\mathbf{r}, t)}{\partial t^{2}}
\end{aligned}
$$

dimana $\mathbf{E}, \mathbf{H}, c$, dan $\varepsilon(\mathbf{r})$ berturut-turut adalah medan listrik, medan magnet, cepat rambat cahaya dan distribusi spasial konstanta dielektrik.

Persamaan (2.1) dan (2.2) dapat memiliki kebergantungan spasial dan temporal yang kompleks. Untungnya, sifat linearitas Persamaan Maxwell membuat solusi spasial dan 
temporal dapat dipisahkan (separable). Variasi medan terhadap waktu dapat diasumsikan bersifat harmonik dengan frekuensi $\omega$ yang memenuhi ansatz:

$$
\begin{aligned}
& \mathbf{E}(\mathbf{r}, t)=\mathbf{E}(\mathbf{r}) e^{i \omega t} \\
& \mathbf{H}(\mathbf{r}, t)=\mathbf{H}(\mathbf{r}) e^{i \omega t}
\end{aligned}
$$

Pilihan solusi harmonik ini menyederhanakan perhitungan matematis tanpa mengurangi generalitas solusi yang didapatkan. Substitusi medan harmonik menghasilkan persamaan gelombang dalam kristal fotonik:

$$
\begin{aligned}
& \frac{1}{\varepsilon(\mathbf{r})} \nabla \times(\nabla \times \mathbf{E}(\mathbf{r}))=\frac{\omega^{2}}{c^{2}} \mathbf{E}(\mathbf{r}) \\
& \nabla \times\left(\frac{1}{\varepsilon(\mathbf{r})} \nabla \times \mathbf{H}(\mathbf{r})\right)=\frac{\omega^{2}}{c^{2}} \mathbf{H}(\mathbf{r})
\end{aligned}
$$

Semua parameter fisis kristal fotonik terkandung di dalam distribusi konstanta dielektrik, $\varepsilon(\mathbf{r})=\varepsilon(\mathbf{r}+\mathbf{R})$ dimana $\mathbf{R}$ adalah periodisitas kisi kristal.

\section{METODE}

Persamaan (2.5) dan (2.6) dapat diselesaikan dalam domain frekuensi dengan menggunakan plane-wave expansion method (Ho dkk., 1990). Berdasarkan Teorema Bloch, sifat periodik konstanta dielektrik mensyaratkan bahwa solusi dari Persamaan (2.5) dan (2.6) berupa gelombang datar yang dimodulasi dengan fungsi periodik. Teorema Bloch mengimplikasikan bahwa medan elektromagnetik di dalam kristal dapat ditentukan jika kita mengetahui distribusinya di dalam satu unit sel. Periodisitas dalam ruang nyata berarti pula periodisitas dalam ruang resiprok, sehingga hanya hubungan dispersi di dalam zona Brillouin (BZ) pertama saja yang perlu dihitung. Lebih lanjut, kita tidak perlu melakukan perhitungan pada setiap titik di dalam BZ karena hubungan dispersi memenuhi simetri grup titik (point group symmetry) kisi yang meliputi rotasi, translasi, dan inversi. Daerah terkecil yang tidak dapat dihubungkan dengan titik simetri disebut dengan irreducible BZ (IBZ).

Perhitungan struktur pita pada setiap titik pada kisi resiprok di dalam IBZ harus dilakukan jika kita ingin menjelaskan perambatan cahaya dalam kristal fotonik. Untuk melihat eksistensi celah pita optik, perhitungan hubungan dispersi hanya perlu dilakukan sepanjang lintasan yang menghubungkan titik-titik simetri tinggi pada sudut IBZ sudah cukup karena titik ekstrim (maksimum dan minimum) berada pada titik-titik tersebut. Perhitungan struktur pita opal dan core-shell opal akan dilakukan dengan menggunakan software MIT Photonic Bands (Johnson dan Joannopoulos, 2001) dengan menggunakan $32 \times 32 \times 32$ gelombang datar.

\section{HASIL DAN DISKUSI}

Berikut adalah hasil optimasi lebar stop band untuk opal dan core-shell opal.

\subsection{Opal}

Struktur pita optik opal sepanjang lintasan yang menghubungkan titik simetri tinggi ditampilkan pada Gambar 4.1(c). Opal dengan struktur $f c c$ diasumsikan terbuat dari partikel polystyrene dengan indeks bias 1,59 dan ruang diantara partikel adalah udara 
dengan indeks bias $\left(n_{\text {med }}=1\right)$. Struktur pita optik ditampilkan dalam frekuensi ternormalisasi $(a / \lambda)$, dimana $a$ dan $\lambda$ berturut-turut adalah konstanta kisi dan panjang gelombang cahaya. Konstanta kisi struktur kristal fcc adalah $\sqrt{2} d$, dimana $d$ diamater partikel.

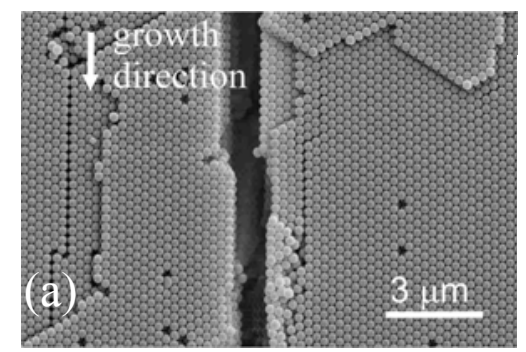

(c)

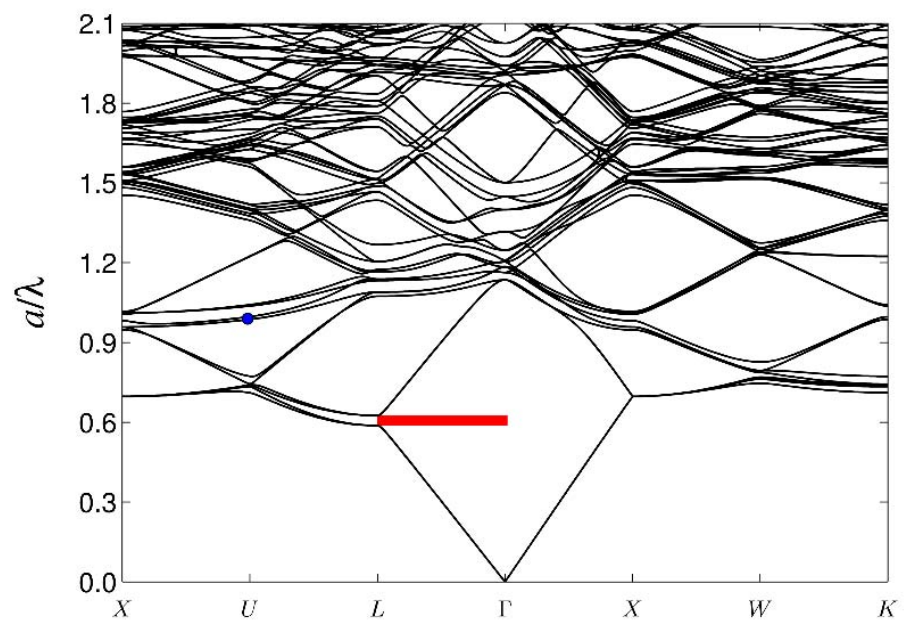

(b)

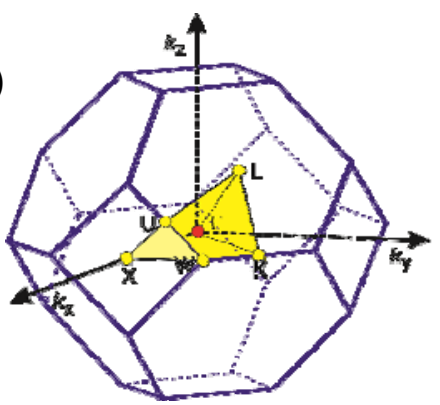

Gambar 4.1. (a) Gambar scanning electron microscope dari polystyrene opal (Muldarisnur dan Marlow, 2011), (b) Brillouin zone kristal fcc opal dimana IBZ ditandai dengan daerah berwarna kuning (Muldarisnur dkk., 2012), dan (c) struktur pita dari opal.

Ada dua celah pita optik parsial (stop band), yaitu pada titik $L$ dan titik $U$. Stop band pada titik $L$ terbentuk antara pita ke-2 dan ke-3, sedangkan dan pada titik $U$ antara pita ke-7 dan ke-8. Celah pita optik opal pada titik $L$ ditunjukkan dengan arsir berwarna merah, sedangkan pada titik $U$ ditunjukkan oleh lingkaran berwarna biru. Berdasarkan hasil SEM, opal cenderung memiliki bidang (111) sejajar dengan substrat, sehingga secara eksperimental arah $\Gamma-L$ berkaitan dengan sinar datang tegak lurus lapisan tipis opal.

Lebar stop band pada titik $L$ dan $U$ untuk opal dari polystyrene sebagai fungsi indeks bias medium sekitar dan jari-jari partikel diperlihatkan pada Gambar 4.2. lebar celah pita optik dinormalisasi dengan frekuensi tengah dari stop band. 

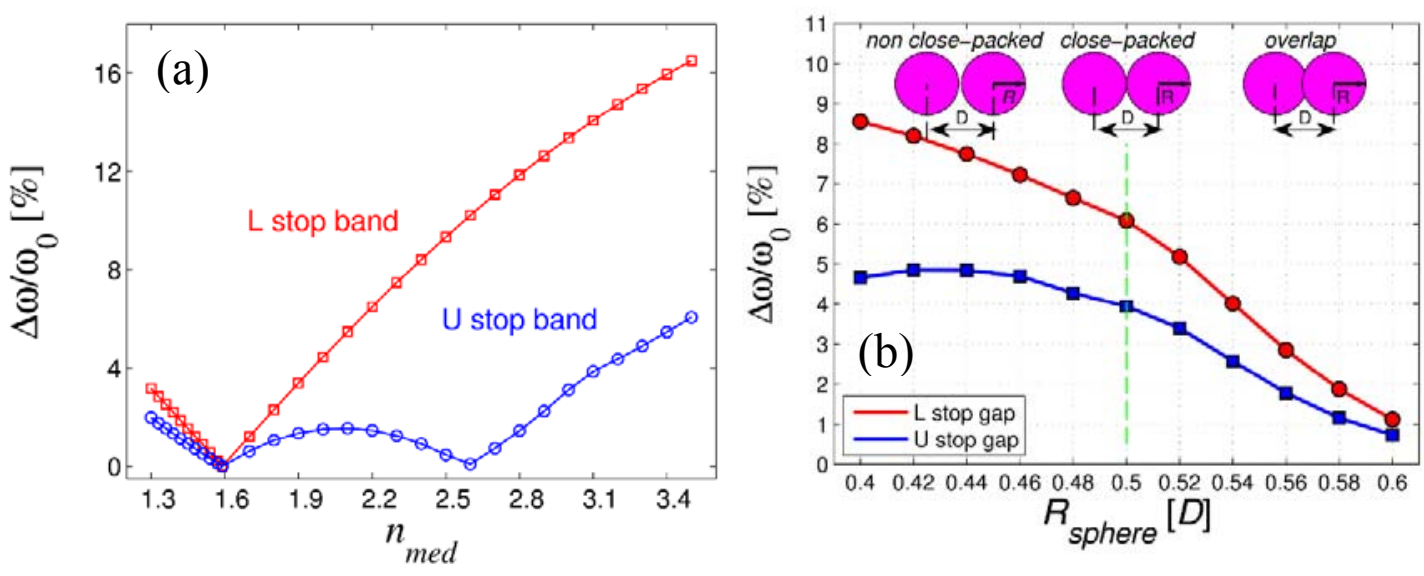

Gambar 4.2. Lebar stop band pada titik $L$ dan $U$ sebagai fungsi: (a) indeks bias medium, dan (b) jari-jari partikel. Jari-jari partikel dinormalisasi dengan jarak pusat-ke-pusat, $D$, dari partikel berdekatan.

Lebar stop band sangat bergantung pada indeks bias ruang diantara partikel (medium). Semakin besar kontras indeks bias antara partikel dan medium, semakin lebar pula stop band. Pada saat indeks bias partikel sama dengan indeks bias medium, stop band pada titk $L$ dan $U$ menghilang karena opal pada prinsipnya tidak lebih dari medium dielektrik homogen. Lebar stop band pada titk $L$ dan $U$ memiliki kebergantungan yang berbeda terhadap indeks bias medium. Stop band pada titik $U$ memiliki dua titik minimum, yaitu pada saat saat $n_{\text {med }}=1,59$ dan 2,6. Munculnya minimum pada saat $n_{\text {med }}=2,6$ berkaitan dengan panjang lintasan optik yang sama di dalam partikel dan medium untuk modus optik frekuensi tinggi.

Gambar 4.2(b) menunjukkan bahwa stop band paling lebar diperoleh pada saat opal terbentuk dari partikel yang tidak saling kontak satu sama lain (Non close-packed opal) yaitu saat diameter partikel lebih kecil dari jarak pisah antara partikel berdekatan. Non close-packed opal terbentuk pada proses deposisi opal dimana ruang diantara partikel masih terisi oleh pelarut (Muldarisnur dan Marlow, 2014). Ketika pelarut menguap, partikel makin mendekat satu sama lain sehingga partikel saling kontak dan membentuk close-packed opal. Pada saat pelarut menguap meninggalkan opal, gaya van der Waals dan tegangan permukaan larutan menekan partikel sehinggan mengakibatkan partikel sedikit terdeformasi (overlap). Lebar stop band berkurang secara drastis ketika deformasi makin besar karena penurunan kontras indeks bias dan jumlah bidang batas antara dua medium berbeda.

\subsection{Core-Shell Opal}

Pada sub-bagian sebelumnya sudah ditunjukkan bahwa stop band opal dengan partikel yang tidak bersentuhan satu sama lain jauh lebih lebar. Sistem non close-packed opal sulit dipertahankan karena terjadinya penguapan pelarut. Hal ini dapat disiasati dengan menumbuhkan core-shell opal. Secara eksperimen, hal ini dapat direalisasikan dengan menggunakan core-shell partikel atau dengan mengevaporasi material lain untuk membentuk shell pada opal yang sudah terbentuk. 


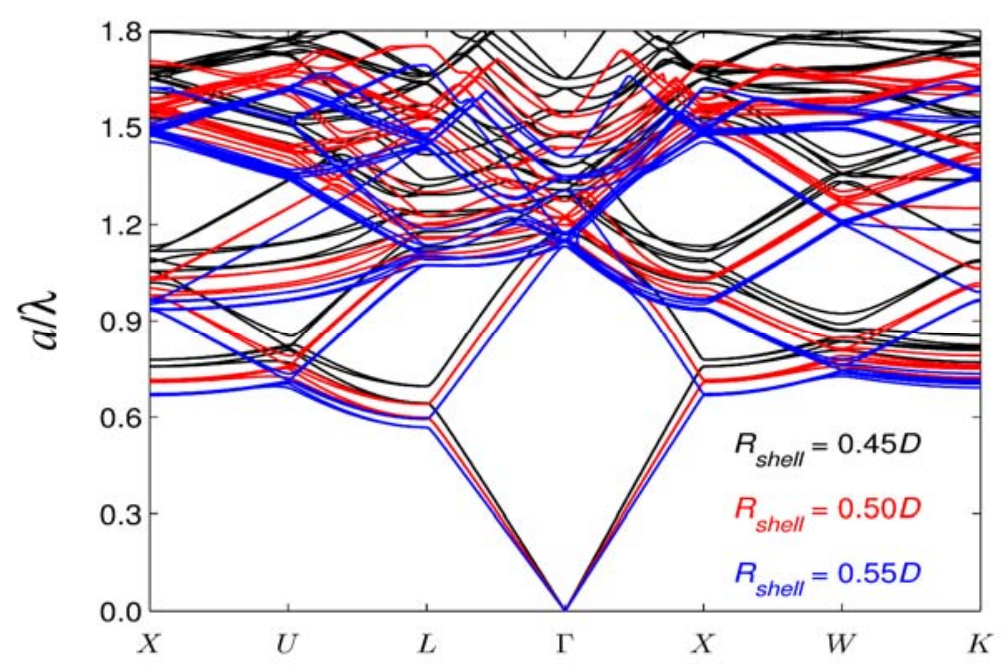

Gambar 4.3. Struktur pita optik core-shell opal dengan variasi jari-jari shell. Jari-jari shell dinormalisasi dengan jarak pisah antara partikel berdekatan $(D)$. Close-packed opal berkaitan dengan jari-jari $R=0,5 D$. Jari-jari core diasumsikan sebesar 0,4 $D$.

Struktur pita optik dari core-shell opal diperlihatkan pada Gambar 4.3. Secara umum struktur pita ini sangat mirip dengan struktur pita opal biasa, perbedaannya hanya pada frekuensi stop band. Hasil simulasi menunjukkan bahwa lebar dan frekuensi stop band berkurang dengan makin besarnya jari-jari shell. Kecenderungan perubahan lebar stop band diperlihatkan pada Gambar 4.4.

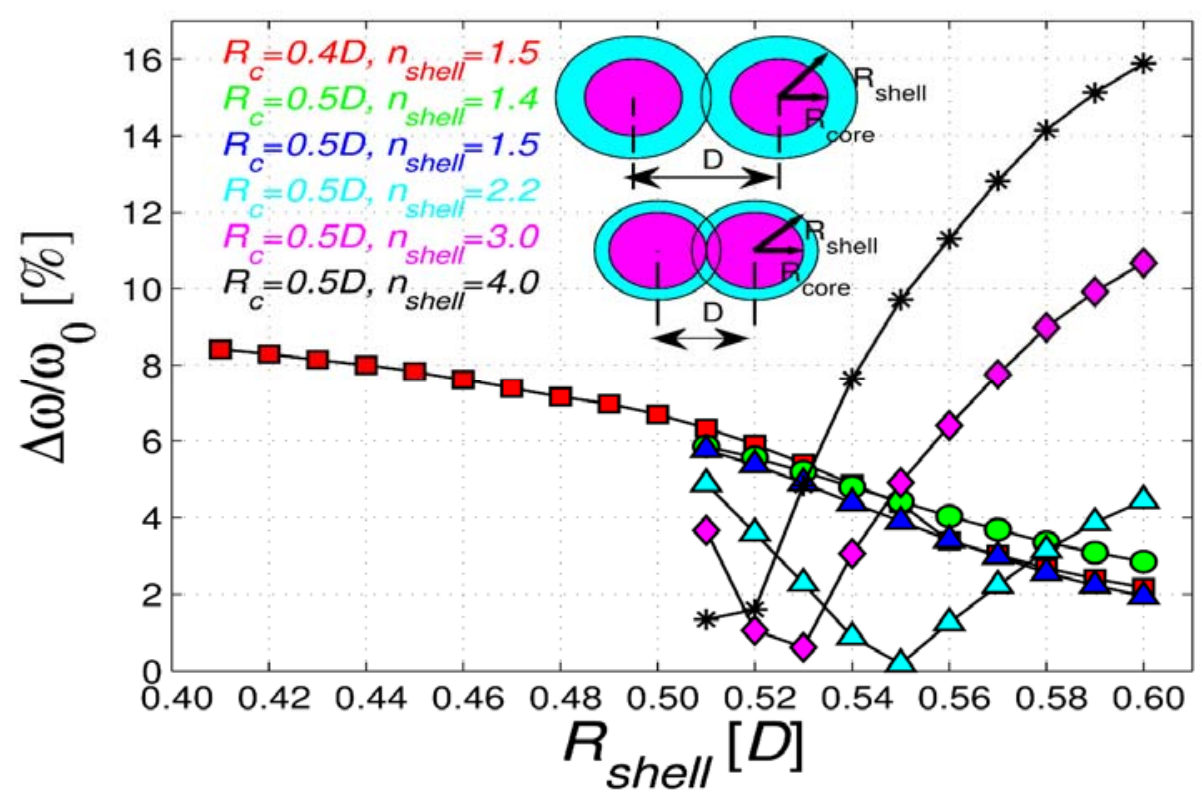

Gambar 4.4. Lebar stop band pada titik L sebagai fungsi jari-jari shell. Definisi dan nilai dari jari-jari core $\left(R_{c}\right)$, jari-jari shell $\left(R_{\text {shell }}\right)$, jarak pisah antar partikel $(D)$ dan indeks bias shell $\left(n_{\text {shell }}\right)$ diberikan di dalam inset. 
Gambar 4.4 menunjukkan lebar stop band untuk dua kondisi berbeda, yaitu jari-jari core lebih kecil dan sama dengan jarak pisah antar partikel. Ada beberapa hal yang dapat disimpulkan, yaitu: (1) Jari-jari core tidak memiliki pengaruh signifikan terhadap lebar stop band, (2) lebar stop band untuk $n_{\text {shell }}<n_{\text {core }}$ berkurang dengan membesarnya $R_{\text {shell }}$

(3) lebar stop band untuk $R_{c}=0,5 D$ bergantung secara signifikan pada $n_{\text {shell }}$ dimana semakin tinggi $n_{\text {shell }}$ semakin lebar stop band, (4) terdapat nilai $R_{\text {shell }}$ dimana lebar stop band bernilai minimum.

Berkurangnya lebar stop band dengan makin besarnya jari-jari shell berkaitan dengan penurunan kontras indeks bias. Tren yang sangat berbeda terlihat ketika opal diberi shell dengan indeks bias lebih tinggi dibanding dengan indeks bias core $\left(n_{\text {core }}=1,59\right)$. Hal ini dikarenakan meningkatnya kontras indeks bias ketika ukuran shell diperbesar. Titik minimum lebar stop band berkaitan dengan samanya lintasan optik pada medium yang berbeda.

Hasil yang didapatkan menunjukkan bahwa penggunaan partikel core-shell tidak efektif untuk memperlebar stop band. Pendekatan yang lebih tepat adalah dengan menumbuhkan opal dengan partikel biasa (homogen) dan kemudian mengevaporasi material yang memiliki indeks bias tinggi seperti logam untuk membentuk shell. Seandainya shell terbuat dari bahan yang deformable sehingga jari-jarinya dapat dikontrol dari luar, maka muncul dan tertutupnya stop band dapat digunakan untuk membuat switch atau transistor optik.

\section{KESIMPULAN}

Lebar stop band dapat dikontrol dengan memvariasikan filling fraction dan kontras indeks bias antara partikel dengan medium sekitar. Opal dengan non close-packed partikel memiliki stop band lebih lebar dibandingkan dengan dua kondisi packing lainnya. Ukuran core tidak terlalu mempengaruhi lebar stop band pada core-shell opal. Untuk mendapatkan opal dengan stop band terlebar, sebaiknya dilakukan deposisi opal menggunakan partikel homogen dan kemudian material dengan indeks bias tinggi dievaporasikan untuk membentuk shell setebal mungkin. Munculnya minimum pada lebar stop band membuat core-shell opal potensial untuk digunakan sebagai switch atau transistor optik.

\section{DAFTAR PUSTAKA}

1. Bagad, S., 2008, Optical Fiber Communication, Technical Publications, Pune.

2. Ho, K.M., Chan, C.T, dan Soukoulis, C.M., 1990, Existence of a Photonic Gap in Periodic Dielectric Structures, Phys. Rev. Lett., Vol. 65, hal. 3152.

3. John, S., 1987, Strong Localization of Photons in certain Disordered Dielectric Superlattices, Phys. Rev. Lett., Vol. 58: 2486-2489.

4. Joannopoulos, J.D., Johnson, S.G., Winn, J.N., dan Meade, R. D., 2008, Photonic Crystals Molding the Flow of Light, Princeton University Press, New Jersey.

5. Johnson S.G. dan Joannopoulos J.D., 2002, Photonic Crystals: The Road from Theory to Practice, Kluwer Academic Publisher, Boston.

6. Johnson S.G. dan Joannopoulos J.D., 2001, Block iterative frequency domain methods for Maxwell's Equation in a planewave basis, Optics Express, Vol. 8: 173190.

7. Muldarisnur, M. dan Marlow, F., 2011, Opal Films Made by the Capillary Deposition Method: Crystal Orientation and Defects, J. Phys. Chem. C, Vol. 11: 414-418. 
8. Muldarisnur, M., Popa, I., dan Marlow, F., 2012, Angle-Resolved Transmission Spectroscopy of Opal Films, Phys. Rev. B, Vol. 86, hal. 024105.

9. Muldarisnur, M. dan Marlow, F., 2014, Observation of nano-dewetting in colloidal crystal drying, Angew. Chem. Int. Ed., Vol. 53: $8761-8764$.

10. Yablonovitch, E., 1987, Inhibited spontaneous emission in solid-state physics and electronics, Phys. Rev. Lett., Vol. 58: 2059-2062. 